\title{
Bronchopulmonary Dysplasia in Premature Infants with Very Low Birth Weight: A Single Centre Retrospective Study in China
}

\author{
Li Shen"1,2*, Tao Bo ${ }^{1 *}$, Senlin Luo', Ruolin Zhang1, Jian Li1" \\ ${ }^{1}$ Division of Neonatology, Children's Medical Center, The Second Xiangya Hospital, Central South University, Changsha, China \\ ${ }^{2}$ Department of Neonatology, The Maternal and Child Health Hospital of Hunan Province, Changsha, China \\ Email: " boily@yeah.net
}

How to cite this paper: Shen, L., Bo, T., Luo, S.L., Zhang, R.L. and Li, J. (2016) Bronchopulmonary Dysplasia in Premature Infants with Very Low Birth Weight: A Single Centre Retrospective Study in China. Open Journal of Pediatrics, 6, 295-307. http://dx.doi.org/10.4236/ojped.2016.64041

Received: October 30, 2016

Accepted: December 2, 2016

Published: December 5, 2016

Copyright $\odot 2016$ by authors and Scientific Research Publishing Inc. This work is licensed under the Creative Commons Attribution-NonCommercial International License (CC BY-NC 4.0). http://creativecommons.org/licenses/by-nc/4.0/ (c) (i) (8) Open Access

\section{Abstract}

To investigate bronchopulmonary dysplasia (BPD) and its treatment with dexamethasone $(\mathrm{DEX})$ in premature infants with birth weight $(\mathrm{BW})<1500 \mathrm{~g}$. We retrospectively reviewed the records of preterm infants admitted to the Division of Neonatology, the Second Xiangya Hospital, Central South University between September 2011 and December 2014. Patients were excluded if they needed oxygen therapy but were lost to follow-up at $\leq 36$ weeks post-menstrual age (PMA) or $<56$ days after birth, or they had severe congenital anomalies. The incidence of BPD was $18 \%$ (37/212). Gestational age (GA) was $<32$ weeks in all BPD patients. GA, BW, and Apgar scores were lower and hospitalization duration and pulmonary surfactant (PS) use were higher in the BPD group than in the non-BPD group $(P<0.05)$. Risk factors for BPD included neonatal respiratory distress syndrome, neonatal pneumonia, positive sputum culture, pulmonary hemorrhage, respiratory failure. Multivariate logistic regression revealed that GA (odds ratio [OR]: 0.479, $P=0.004$ ) and neonatal respiratory distress syndrome (OR: 6.146, $P=0.043$ ) were independent risk factors for BPD. DEX was administered to 26 patients after the diagnosis of BPD. After one and two weeks of DEX treatment, the oxygen requirement had significantly reduced compared to the week prior to treatment $(P<0.05)$, while during treatment, the weight gain rate and weight gain efficiency slower significantly than that during either of the two preceding weeks $(P<0.001)$. These results suggest that low GA was the most important risk factor for BPD, DEX reduced oxygen dependency but decreased weight gain. 


\section{Keywords}

Bronchopulmonary Dysplasia, Very Low Birth Weight Infants, Oxygen Therapy,

Dexamethasone, Weight Gain

\section{Introduction}

With improvements in neonatal emergency care, preterm infants, particularly very low birth weight (VLBW) infants $(<1500 \mathrm{~g})$, now have significantly increased survival rates. According to the foreign studies, Bronchopulmonary dysplasia (BPD) remains a major threat because it adversely affects the prognosis of VLBW infants; similar work in domestic of this issue is relatively less. Furthermore, specific treatment methods are lacking, and research into the prevention and amelioration of BPD is urgently required [1].

This retrospective study assessed the prevalence of BPD in VLBW infants over the last 3 years, analyzed the risk factors and clinical features associated with BPD, and determined the short-term efficacy and safety of dexamethasone (DEX) treatment. The aim of this study was to summary clinical evidence for an optimal prevention and treatment therapy of BPD.

\section{Patients and Methods}

\subsection{Diagnostic Criteria for BPD}

The diagnosis of BPD is based on the need for supplemental oxygen for at least 28 days after birth, and its severity is graded according to the respiratory support required at 36 weeks post-menstrual age (PMA) (GA $<32$ weeks) or at 56 days after birth (GA $\geq 32$ weeks) as follows: 1) mild, breathing room air; 2) moderate, $\mathrm{FiO}_{2}<0.3$; and 3) severe, $\mathrm{FiO}_{2} \geq 0.3$ with mechanical ventilation if required [2].

\subsection{Study Protocol}

We collected the clinical data of premature infants who had a birth weight of $<1500 \mathrm{~g}$ and were treated in the neonatal intensive care unit at our hospital between September $1^{\text {st }}, 2011$, and December $31^{\text {st }}, 2014$. The inclusion criteria were a hospital stay beyond 36 weeks PMA (GA > 32 weeks) or 56 days after birth (GA $\geq 32$ weeks), or discharge with no need for additional oxygen within this period. Patients were excluded if they still required oxygen therapy but were discharged before 36 weeks PMA (GA $<32$ weeks) or 56 days after birth ( $G A \geq 32$ weeks). Patients with severe congenital anomalies or with missing clinical information (i.e., degree of prematurity, type of oxygen therapy) were also excluded. The patients were categorized into a BPD group and a non-BPD group, according to the diagnostic criteria mentioned above. This study protocol was approved by the ethics committee of Central South University.

\subsection{Statistical Analysis}

The results are expressed as means with SD or medians with interquartile for conti- 
nuous data and frequencies for discrete data, data were analyzed using t-tests, ChiSquare test, one-way analysis of variance, Fisher's exact test and multivariate logistic regression analysis. All statistical analyses were performed using the SPSS 19.0 software package (SPSS Inc., Chicago, IL, USA), with $\alpha=0.05$ for two-tailed tests. $P$-values $<0.05$ were considered statistically significant.

\section{Results}

\subsection{General Characteristics}

Between September $1^{\text {st }}, 2011$ and December31 $1^{\text {st }}, 2014,273$ premature infants with a birth weight of $<1500 \mathrm{~g}$ were treated at our hospital, of whom 212 infants met the inclusion criteria for our study; 114 were boys, and 98 were girls. Their median GA was $30^{+4}$ weeks (interquartile range: $29^{+1}$ to 32 weeks), and their median birth weight was $1315 \mathrm{~g}$ (interquartile range: 1160 to $1407 \mathrm{~g}$ ). Thirty-seven patients met the diagnostic criteria for BPD, giving an incidence of $18 \%$ (37/212). The BPD incidence in infants with a birth weight of $<1000 \mathrm{~g}$ was $37 \%(6 / 16)$, while the incidence in infants with a birth weight of 1000-1499 $\mathrm{g}$ was $16 \%(31 / 196)$.

All cases of BPD occurred in infants born at a GA of $<32$ weeks, in which the incidence of BPD was $23 \%$ (37/160). The incidence of BPD was $56 \%(9 / 16)$ in infants born at a GA of $\leq 28$ weeks, $31 \%$ in infants born between $28^{+1}$ and 30 weeks (22/72), and only $8 \%$ in infants born at over $30^{+1}(6 / 72)$.

\subsection{Clinical Characteristics and Risk Factors Associated with BPD}

Table 1 reveals the differences between BPD and non-BPD group. GA, birth weight, and 1and 5-min Apgar scores were significantly lower and the duration of hospitalization was significantly higher in the BPD group than in the non-BPD group $(P<0.05$ for all). In addition, the rates of neonatal respiratory distress syndrome (NRDS), neonatal pneumonia, positive sputum culture, pulmonary hemorrhage, apnea, respiratory failure, sepsis, blood-stained amniotic fluid, and use of pulmonary surfactant (PS) were higher in the BPD group ( $P<0.05$ for all). The mothers of children in the BPD group were less likely to have had pregnancy-induced hypertension and delivered small for gestational age (SGA) infants than the mothers of children in the non-BPD group $(P<$ 0.05). Multivariate logistic regression analysis revealed that GA (odds ratio [OR] = $0.479, P=0.004,95 \%$ confidence interval [CI]: $0.291-0.789)$ and NRDS (OR $=6.146, P$ $=0.043,95 \%$ CI: 1.125 - 33.574) were independent risk factors for BPD (Table 2).

The cumulative duration of oxygen therapy and mechanical ventilation within each of $7,14,21,28$ days after birth were significantly greater in the BPD group than in the non-BPD group $(P<0.001$; Figure 1 and Figure 2$)$.

\subsection{Treatment of BPD with DEX}

Adequate information was provided to the guardian of each patient regarding to DEX benefits and risks, informed consent was obtained then, 26 infants diagnosed with BPD 
Table 1. Univariate analysis of factors related to BPD.

\begin{tabular}{|c|c|c|c|c|c|}
\hline & $\begin{array}{l}\text { BPD group } \\
\quad(\mathrm{n}=37)\end{array}$ & $\begin{array}{l}\text { Non-BPD group } \\
\quad(\mathrm{n}=175)\end{array}$ & $t$ value & $x^{2}$ & $P$ \\
\hline GA at birth (wk) & $29.0 \pm 1.1$ & $31.1 \pm 2.0$ & 9.081 & & $<0.001$ \\
\hline Birth weight (g) & $1205.8 \pm 179.0$ & $1292.6 \pm 150.7$ & 2.748 & & 0.008 \\
\hline 1-min Apgar score & $5.9 \pm 2.0$ & $6.8 \pm 1.7$ & 2.824 & & 0.005 \\
\hline 5-min Apgar score & $7.4 \pm 2.1$ & $8.6 \pm 1.2$ & 3.235 & & 0.002 \\
\hline Paternal age (yr) & $34.4 \pm 5.8$ & $32.4 \pm 5.8$ & 1.834 & & 0.068 \\
\hline Maternal age (yr) & $30.8 \pm 4.4$ & $29.4 \pm 4.9$ & 1.688 & & 0.093 \\
\hline Length of hospital stay (d) & $67.7 \pm 20.9$ & $43.1 \pm 14.6$ & 6.801 & & $<0.001$ \\
\hline Male (\%) & $68 \%(25 / 37)$ & $51 \%(89 / 175)$ & & 3.431 & 0.064 \\
\hline Small for gestational age (\%) & $8 \%(3 / 37)$ & $42 \%(73 / 175)$ & & 14.99 & $<0.001$ \\
\hline Assisted reproduction (\%) & $27 \%(10 / 37)$ & $26 \%(45 / 175)$ & & 0.027 & 0.869 \\
\hline Fetal distress (\%) & $16 \%(6 / 37)$ & $27 \%(48 / 175)$ & & 2.023 & 0.155 \\
\hline PROM (\%) & $54 \%(20 / 37)$ & $43 \%(75 / 175)$ & & 1.548 & 0.213 \\
\hline Blood-stained amniotic fluid (\%) & $13 \%(4 / 31)$ & $2 \%(3 / 166)$ & & 6.426 & $0.011^{\mathrm{a}}$ \\
\hline $\begin{array}{c}\text { Placenta previa/placental } \\
\text { abruption (\%) }\end{array}$ & $29 \%(8 / 28)$ & $13 \%(17 / 135)$ & & 3.412 & $0.065^{\mathrm{a}}$ \\
\hline Umbilical cord abnormality (\%) & $19 \%(5 / 26)$ & $14 \%(20 / 138)$ & & 0.102 & $0.750^{\mathrm{a}}$ \\
\hline UU infection (\%) & $0 \%(0 / 37)$ & $2 \%(3 / 175)$ & & 0.643 & $1.000^{\mathrm{b}}$ \\
\hline Gestational diabetes (\%) & $16 \%(6 / 37)$ & $17 \%(30 / 175)$ & & 0.019 & 0.892 \\
\hline $\begin{array}{l}\text { Hypertensive disorders of } \\
\text { pregnancy (\%) }\end{array}$ & $16 \%(6 / 37)$ & $33 \%(57 / 175)$ & & 3.912 & 0.048 \\
\hline $\begin{array}{c}\text { Thyroid dysfunction in } \\
\text { pregnancy (\%) }\end{array}$ & $11 \%(4 / 37)$ & $7 \%(12 / 175)$ & & 0.235 & $0.628^{\mathrm{a}}$ \\
\hline $\begin{array}{l}\text { Intrahepatic cholestasis } \\
\text { of pregnancy (\%) }\end{array}$ & $0 \%(0 / 37)$ & $3 \%(6 / 175)$ & & 0.356 & $0.550^{\mathrm{a}}$ \\
\hline Prenatal GC (\%) & $62 \%(21 / 34)$ & $56 \%(84 / 149)$ & & 0.329 & 0.556 \\
\hline NRDS (\%) & $89 \%(33 / 37)$ & $34 \%(60 / 175)$ & & 37.389 & $<0.001$ \\
\hline Neonatal pneumonia (\%) & $95 \%(35 / 37)$ & $58 \%(102 / 175)$ & & 17.612 & $<0.001$ \\
\hline $\begin{array}{c}\text { Positive sputum } \\
\text { bacterial culture (\%) }\end{array}$ & $32 \%(12 / 37)$ & $8 \%(14 / 175)$ & & 14.750 & $<0.001^{\mathrm{a}}$ \\
\hline Pulmonary hemorrhage (\%) & $11 \%(4 / 37)$ & $1 \%(2 / 175)$ & & 7.163 & $0.007^{\mathrm{a}}$ \\
\hline Apnea (\%) & $81 \%(30 / 37)$ & $51 \%(90 / 175)$ & & 10.933 & 0.001 \\
\hline Respiratory failure (\%) & $54 \%(20 / 37)$ & $13 \%(22 / 175)$ & & 33.083 & $<0.001$ \\
\hline Sepsis (\%) & $40 \%(15 / 37)$ & $22 \%(38 / 175)$ & & 5.773 & 0.016 \\
\hline Thrombocytopenia (\%) & $30 \%(11 / 37)$ & $26 \%(46 / 175)$ & & 0.184 & 0.668 \\
\hline NEC (\%) & $0 \%(0 / 37)$ & $3 \%(5 / 175)$ & & 1.083 & $0.590^{\mathrm{b}}$ \\
\hline PDA (\%) & $11 \%(4 / 37)$ & $6 \%(11 / 175)$ & & 0.378 & 0.534 \\
\hline Use of PS (\%) & $81 \%(30 / 37)$ & $35 \%(62 / 175)$ & & 25.914 & $<0.001$ \\
\hline
\end{tabular}

al $\leq \mathrm{t}<5$, continuity correction; bt $<1$, Fisher exact test. BPD, bronchopulmonary dysplasia; GA, gestational age; NRDS, neonatal respiratory distress syndrome; NEC, necrotizing enterocolitis; PDA, patent ductus arteriosus; PS, pulmonary surfactant; PROM, premature rupture of membranes; UU infection, Ureaplasma urealyticum infection. 
Table 2. Results of the multiple logistic regression for risk factors for BPD.

\begin{tabular}{cccccc}
\hline & B-value & SE & $P$-value & OR & $95 \%$ CI \\
\hline GA at birth (wk) & -0.736 & 0.255 & 0.004 & 0.479 & $0.291-0.789$ \\
Birth weight (g) & 0.002 & 0.002 & 0.183 & 1.002 & $0.999-1.006$ \\
1-min Apgar score & -0.118 & 0.245 & 0.629 & 0.888 & $0.550-1.436$ \\
5-min Apgar score & -0.109 & 0.255 & 0.669 & 0.897 & $0.543-1.479$ \\
NRDS (\%) & 1.816 & 0.866 & 0.036 & 6.146 & $1.125-33.574$ \\
Neonatal pneumonia (\%) & -0.090 & 0.991 & 0.928 & 0.914 & $0.131-6.376$ \\
Positive sputum bacterial culture & 1.110 & 0.595 & 0.062 & 3.035 & $0.945-9.744$ \\
Pulmonary hemorrhage (\%) & 1.254 & 1.232 & 0.309 & 3.504 & $0.314-39.161$ \\
Apnea (\%) & 0.619 & 0.618 & 0.317 & 1.857 & $0.552-6.239$ \\
Respiratory failure (\%) & 1.092 & 0.585 & 0.062 & 2.981 & $0.948-9.378$ \\
Sepsis (\%) & -0.757 & 0.590 & 0.200 & 0.469 & $0.148-1.491$ \\
Blood-stained amniotic fluid (\%) & -0.882 & 0.460 & 0.055 & 0.414 & $0.168-1.020$ \\
hypertensive disorders of & 0.080 & 0.775 & 0.918 & 1.083 & $0.237-4.946$ \\
pregnancy (\%) & -0.280 & 0.877 & 0.749 & 0.755 & $0.135-4.216$ \\
Small for gestational age (\%) & 0.642 & 0.713 & 0.368 & 1.900 & $0.469-7.689$ \\
Use of PS (\%) & & & & & \\
\hline
\end{tabular}

BPD: Bronchopulmonary dysplasia; NRDS: Neonatal respiratory distress syndrome; PS: Pulmonary surfactant.

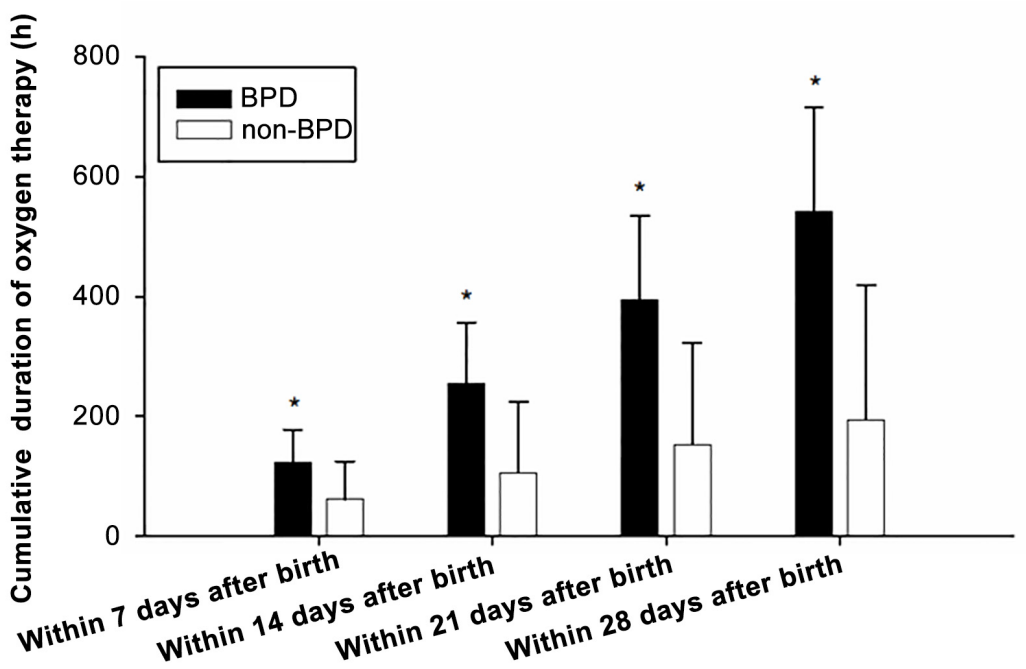

Figure 1. Comparison of cumulative duration of oxygen therapy (h) between the bronchopulmonary dysplasia (BPD) and non-BPD group, ${ }^{*}$ compare with nonBPD group, $P<0.001$.

were treated with intravenous DEX, with an initial dose at $0.15 \mathrm{mg} / \mathrm{kg} / \mathrm{d}$ for the majority, decreasing $0.05 \mathrm{mg} / \mathrm{kg} / \mathrm{d}$ every three days, after daily dose reaching $0.05 \mathrm{mg} / \mathrm{kg} / \mathrm{d}$, then maintain daily injection until oxygen supplementation or the machine was withdrawn. Blood pressure, blood glucose, blood-electrolytes, body weight and gastrointestinal reaction were monitored, then all of them were included in a designed long-term 
follow-up study. During this treatment, neither diuretics nor fluid restriction were used excepting complicated with edema, nor inhaled nitric oxide and caffeine, nutrition support was as usual. The median age of these children on day 1 of the treatment was 44.5 $\mathrm{d}$ (range, $29-75 \mathrm{~d}$ ). The median duration of DEX treatment was $8 \mathrm{~d}$ (range, $2-32 \mathrm{~d}$ ), and the median cumulative dosage of DEX was $0.92 \mathrm{mg} / \mathrm{kg}$ (range, $0.55-2.44 \mathrm{mg} / \mathrm{kg}$ ), with a median dose of $0.11 \mathrm{mg} / \mathrm{kg} / \mathrm{d}$ (range, $0.07-0.39 \mathrm{mg} / \mathrm{kg} / \mathrm{d}$ ). After the first course of DEX treatment, oxygen supplementation was withdrawn in 18 patients after a median time of $5 \mathrm{~d}$ (range, $1-45 \mathrm{~d}$ ). Seven patients remained on oxygen treatment via a nasal cannula; six of these patients received a repeated course of DEX, and three of them were successfully weaned off oxygen therapy. One patient required further mechanical ventilation after discharge.

As shown in Figure 3, there was no significant difference in the duration of oxygen therapy in patients 1 week before the commencement of DEX treatment compared to 2 weeks before treatment started $(149.2 \pm 36.5 \mathrm{~h}$ vs. $150.4 \pm 36.2 \mathrm{~h} ; P=0.938)$. After one week of DEX treatment, the durations of oxygen treatment $(117.3 \pm 56.2 \mathrm{~h})$ had significantly reduced compared to that of the preceding week (untreated, $P<0.05$ ). After 2 weeks of DEX therapy, oxygen treatment durations were even shorter compared to the week prior to treatment $(55.54 \pm 70.13 \mathrm{~h} ; P<0.001)$.

With regards to weight gain, as shown in Figure 4, there was no difference in the weight gain rates in the 2 weeks preceding the administration of DEX $(13.5 \pm 5.0 \mathrm{~g} / \mathrm{kg} / \mathrm{d}$ vs. $15.8 \pm 7.6 \mathrm{~g} / \mathrm{kg} / \mathrm{d}$ for 1 and 2 weeks prior to DEX treatment, respectively; $P=0.203$ ). After the first week of DEX treatment, the rate of weight gain slowed significantly compared to both 1 and 2 weeks before the intervention $(6.3 \pm 6.6 \mathrm{~g} / \mathrm{kg} / \mathrm{d} ; P<0.001)$.

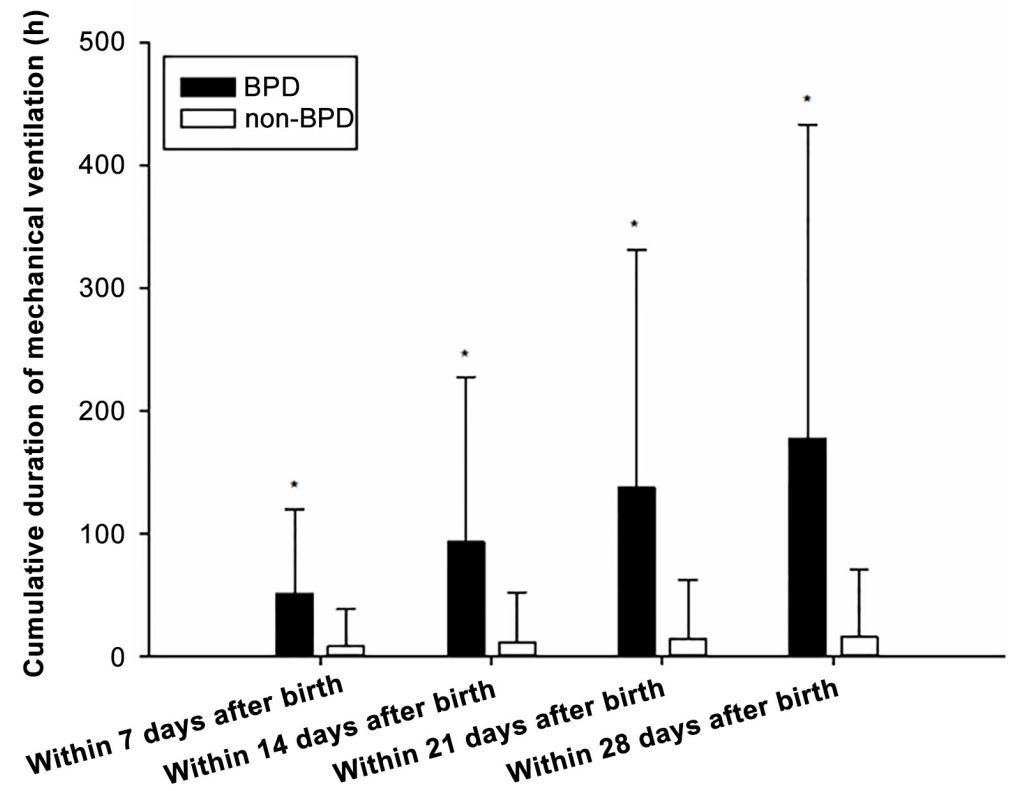

Figure 2. Comparison of cumulative duration of mechanical ventilation (h) between the bronchopulmonary dysplasia (BPD) and non-BPD group. ${ }^{\star} \mathrm{Com}-$ pare with non-BPD group, $P<0.001$. 


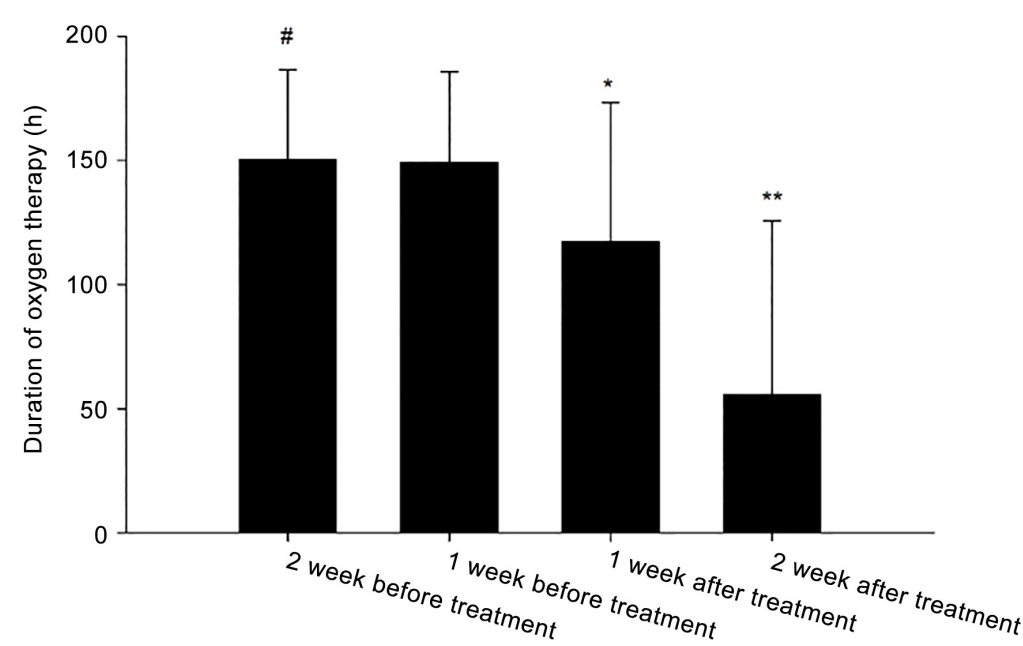

Figure 3. Comparison of duration of oxygen therapy (h) before and after dexamethasone treatment in bronchopulmonary dysplasia infants. ${ }^{*}$ Compared with 1 week before treatment, $P>0.05$. ${ }^{\star}$ Compared with 2 week and 1 week before treatment, $P<0.05$. ${ }^{*}$ Compared with 2 week and1 week before treatment, $P<$ 0.001

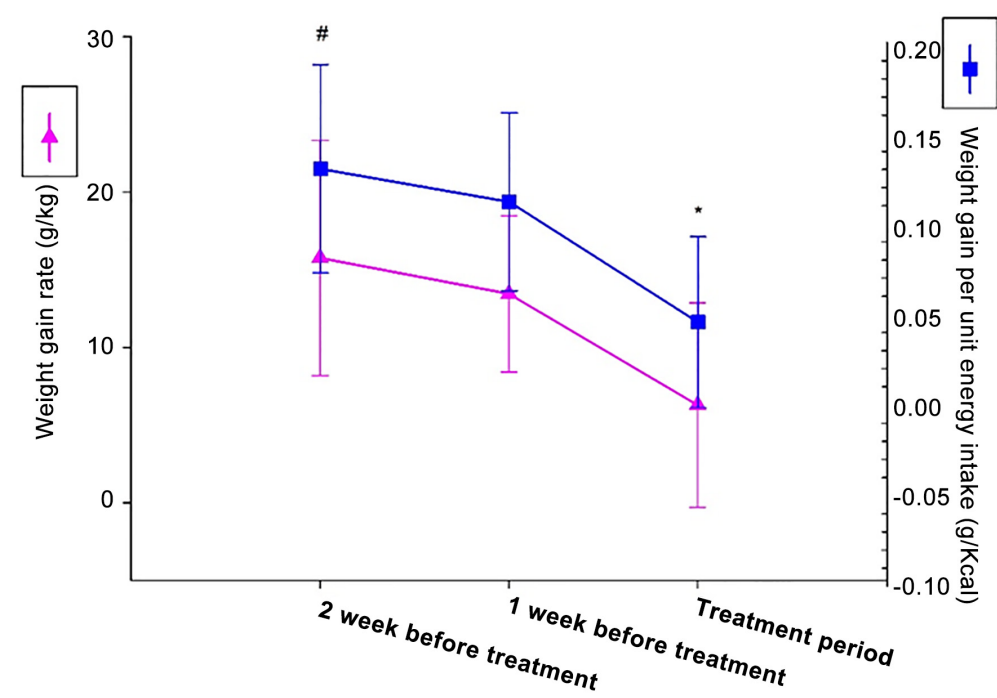

Figure 4. Comparison of weight gain related indicates before and after dexamethasone treatment in bronchopulmonary dysplasia infants. "Compared with 1 week before treatment, $P>0.05$. ${ }^{\star}$ Compared with 1 week before treatment, $P<0.001$.

As show in Figure 4, an analysis of the changes in weight gain before and after the use of DEX showed that the weight gain per unit of energy intake in the week before the initiation of DEX therapy $(0.11 \pm 0.05 \mathrm{~g} / \mathrm{kcal})$ did not significantly differ from that 2 weeks before treatment was started $(0.13 \pm 0.06 \mathrm{~g} / \mathrm{kcal} ; P=0.205)$. During DEX treatment, the weight gain per unit of energy intake was significantly lower $(0.05 \pm 0.05$ $\mathrm{g} / \mathrm{kcal})$ than that during either of the two preceding weeks $(P<0.001)$. 
The following complications occurred in the 26 BPD patients who were treated with DEX: feeding intolerance ( $\mathrm{n}=3$, including one case of abdominal distension), increased white blood cell count $(n=5)$, electrolyte imbalance $(n=3$; hyponatremia, $n=1$; hyperkalemia, $\mathrm{n}=1$; and hypocalcemia, $\mathrm{n}=1)$, hyperglycemia $(\mathrm{n}=2)$ and localized edema ( $\mathrm{n}=3$; limb edema, $\mathrm{n}=1$; edema of both lower limbs and the lumbosacral region, $\mathrm{n}=1$; edema of the lower limbs and perineal edema, $\mathrm{n}=1$ ). There were no cases of upper gastrointestinal bleeding/perforation, infection or hypertension.

\section{Discussion}

Since Northway first described BPD in 1967, clinicians have gradually developed a deepened understanding of this condition. Different incidences of BPD have been reported in different time periods, countries, regions and organizations [3] [4] [5]. The current study selected preterm infants with a birth weight of $<1500 \mathrm{~g}$, and patients with BPD accounted for $18 \%$ of the study population. In a report from Korea, Choi et al. determined that the incidence of BPD in VLBW infants was 18\% between 2007 and 2008 [6], which was consistent with our findings. However, other studies have reported markedly different findings. Vakrilova et al. from the Maternity Children's Hospital in Sofia, Bulgaria reported that the incidence of BPD in VLBW infants at 28 days after birth was $26.8 \%$ between 2008 and 2010 [7]. A study from India reported that the incidence of BPD was as high as $52.8 \%$ [8]. These high incidence rates suggest that BPD is a major complication in VLBW infants worldwide and can seriously affect the prognosis of premature children.

In the early days of research into BPD, high concentrations of oxygen and positive pressure ventilation were determined to be the major causes. BPD was equivalent to "oxygen toxicity," a serious complication of NRDS, with pathological findings of obstructive bronchitis and pulmonary fibrosis [9]. After exogenous PS became widely used clinically, the incidence of this "classical BPD" gradually reduced. Instead, "new BPD" has increased clinical focus. The dominant pathological finding in "new BPD" isan arrest in alveolar development, resulting in lungs with large and simplified airspaces with relatively infrequent fibrosis [10]. Currently, most researchers agree with the hypothesis that BPD is a developmental disorder that results from interference with the process of pulmonary maturation, leading to developmental maturation abnormalities of the structures and functions of the distal lung parenchyma [11] [12] [13]. Thus, lung injuries in BPD are attributable to hyperoxia, barotrauma, stress and pulmonary immaturity, as well as infections, intrauterine hypoxia and patent ductus arteriosus [14] [15] [16] [17] [18].

This study demonstrated that BPD occurred in premature infants born at a GA of $\leq 32$ weeks; GA was significantly lower in the BPD group than in the non-BPD group. Furthermore, the lower was the GA, the higher the incidence of BPD. The incidence of BPD in infants with a GA of $\leq 28$ weeks was $56 \%$. Logistic regression analysis showed that GA was an independent risk factor for the occurrence of BPD. Thus, the factor that was most closely related to the development of BPD in our study population was con- 
sistent with the generally accepted view [19] [20]. The consequences of BPD on infants born at early GA stages emphasizes that this outcome should be considered in all patients with a low GA, and stronger precautions against preterm birth are vital.

In the current study, patients in the BPD group had a higher probability of developing NRDS, neonatal pneumonia, pulmonary hemorrhage and other respiratory diseases, as well as having a positive sputum culture, than patients in the non-BPD group. Logistic regression analysis showed that NRDS was an independent risk factor for BPD, which suggests that the incidence of BPD in premature lungs depends on a variety of factors that lead to lung injury.

Patients in the BPD group were more likely to have received PS than patients in the non-BPD group. This finding was not in accordance with previous studies that have shown that PS protects against BPD [21] [22]. In the present study, the higher rate of PS use in the BPD group was related to the lower GA and higher incidence of NRDS in this group. These factors necessitated the use of PS for the prevention and treatment of NRDS. Thus, it would be erroneous to conclude that PS use increased the incidence of BPD.

Increasing evidence has been published that suggests an adverse intrauterine environment damages lung development, especially alveolar development, and leads to persistent changes in lung structure and postnatal respiratory compromise; thereby, SGA premature infants have been reported to have an increased incidence of BPD [23] [24]. As the respiratory dysfunction persists during postnatal development, the incidence of respiratory-related illnesses and mortality in adulthood is also significantly increased in SGA infants [25]. Even children with an appropriate for gestational age (AGA) weight have a significantly higher probability of BPD if their birth weight is less than the average weight for their GA [26]. Although the relationship between SGA weight and late pulmonary function abnormalities is unknown, evidence from animal models has indicated that intrauterine growth retardation factors, including malnutrition and hypoxia, can affect fetal lung development, impair the development of the terminal alveoli, inhibit the synthesis of PS, reduce the expression of surfactant, and induce inflammatory injury, thus increasing the risk of BPD [27] [28] [29] [30]. However, in our study, the rates of maternal pregnancy-induced hypertension and SGA infants were significantly lower in the BPD group than in the non-BPD group. In this view, although chronic intrauterine hypoxia and other adverse factors may directly affect fetal lung development, SGA children still will be more likely to have a more mature lung than AGA infants while with a similar birth weight, and lower GA may have a greater impact on lung development than other potentially injurious factors, such as intrauterine growth retardation, further prospective studies with larger sample sizes are needed to investigate whether it is true.

Oxygen toxicity as a result of high oxygen concentrations and pressure injuries due to positive pressure ventilation are considered to be important factors in the pathogenesis of BPD. This current study showed significant differences between the BPD and the non-BPD group with regards to the cumulative duration of oxygen therapy and 
mechanical ventilation in the first 4 postnatal weeks. These findings suggest that oxygen-related lung injury is an important risk factor for $\mathrm{BPD}$, the requirement for supplemental oxygen or mechanical ventilation, as one of its main clinical features, increased the duration and the expense of hospitalization indirectly. DEX, a long-acting glucocorticoid, has been used in clinic for it could significantly shorten the duration of mechanical ventilation and reduce the incidence of BPD and death [31] [32]. However, the potential adverse outcome in neurodevelopment make the clinician more prudently. In this study, our clinicians would discuss the potential benefits, risks and relevant solutions of DEX with each guardian of BPD infants. 26 BPD infants received DEX treatment as a therapeutic intervention since their parent signed a written agreement.

A comparison of the data obtained before and after DEX treatment revealed that the duration of oxygen therapy and mechanical ventilation were significantly reduced in infants diagnosed with BPD, effectively reducing their oxygen dependency. However, these current results do not enable conclusions to be made regarding whether DEX can alleviate BPD severity or improve long-term pulmonary outcomes, such as lung function. Future case-control studies will be required to confirm these findings.

Hypertension, gastrointestinal perforation and other serious adverse short-term complications did not occur after DEX treatment in our patients. However, weight gain rate was significantly lower after DEX treatment than before this treatment, and the weight gain per unit energy intake, which was calculated to indicate the amount of body weight gained per kilojoule of energy consumed, reflecting feed efficiency, was significantly declined as well. As we know, The adrenocorticoid receptor(ACR) is an important nuclear transcription factor. In the absence of glucocorticoids, ACR binds to heat shock proteins (HSPs) in the cytoplasm, such as HSP-90, HSP-70 and FKBP52, whichare rapidly translocated into the nucleus by importin molecules. In the nucleus, they bind to hormone response units, regulate target gene expression and participate in essential cellular processes, including energy metabolism, protein synthesis and signal transduction [33]. Thus, we suppose that the increased energy metabolismin the body caused by DEX, such as inhibition on anabolism and enhancement on catabolism of protein, may be the main cause for the deceased weight gain rate and feed efficiency. Further analysis of the intrinsic mechanism was also required. Anyway, for effective weight gain during DEX treatment, the supply of nutrients must be sufficient, evenaugmented to some extent.

\section{Conclusion}

$\mathrm{BPD}$ is a common complication in premature children with a birth weight of $<1500 \mathrm{~g}$, and GA is an important predictor of BPD. The use of DEX can significantly shorten the duration of oxygen therapy in children with $\mathrm{BPD}$, but may reduce weight gain.

\section{Fund}

This study was supported by the Science Technology Support Plan program of Hunan Province, No.2015SF2019-2. 


\section{References}

[1] Kugelman, A. and Durand, M. (2011) A Comprehensive Approach to the Prevention of Bronchopulmonary Dysplasia. Pediatic Pulmonology, 46, 1153-1165. https://doi.org/10.1002/ppul.21508

[2] Jobe, A.H. and Bancalari, E. (2001) Bronchopulmonary Dysplasia. American Journal of Respiratory Critical Care Medicine, 163, 1723-1729.

https://doi.org/10.1164/ajrccm.163.7.2011060

[3] Avery, M.E., Tooley, W.H., Keller, J.B., Hurd, S.S., Bryan, M.H., et al. (1987) Is Chronic Lung Disease in Low Birth Weight Infants Preventable? A survey of Eight Centers. Pediatrics, 79, 26-30.

[4] Gortner, L., Misselwitz, B., Milligan, D., Zeitlin, J., Kollee, L., et al. (2011) Rates of Bronchopulmonary Dysplasia in Very Preterm Neonates in Europe: Results from the MOSAIC Cohort. Neonatology, 99, 112-117. https://doi.org/10.1159/000313024

[5] Zysman-Colman, Z., Tremblay, G.M., Bandeali, S. and Landry, J.S. (2013) Bronchopulmonary Dysplasia-Trends Over Three Decades. Paediatric \& Child Health, 18, 86-90.

[6] Choi, C.W., Kim, B.I., Kim, E.K., Song, E.S. and Lee, J.J. (2012) Incidence of Bronchopulmonary Dysplasia in Korea. Journal of Korean Medical Science, 27, 914-921. https://doi.org/10.3346/jkms.2012.27.8.914

[7] Vakrilova, L., Slancheva, B., Hitrova, S., Popivanova, A., Emilova, Z., et al. (2013) Frequency, Severity and Risk Factors for Bronchopulmonary Dysplasia Among Very Low Birth Weight Premature Infants Admitted in the NICU of the University Obstetrics and Gynecology Hospital, Sofia. Akusherstvoi Ginekologiia (Sofiia), 52, 21-29.

[8] Demirel, N., Bas, A.Y. and Zenciroglu, A. (2009) Bronchopulmonary Dysplasia in Very Low Birth Weight Infants. Indian Journal of Pediatrics, 76, 695-698.

https://doi.org/10.1007/s12098-009-0110-5

[9] Northway Jr., W.H. Rosan, R.C. and Porter, D.Y. (1976) Pulmonary Disease Following Respirator Therapy of Hyaline-Membrane Disease. The New England Journal of Medicine, 7, 357-368.

[10] Philip, A.G. (2012) Bronchopulmonary Dysplasia: Then and Now. Neonatology, 102, 1-8. https://doi.org/10.1159/000336030

[11] Shaw, G.M. and O'Brodovich, H.M. (2013) Progress in Understanding the Genetics of Bronchopulmonary Dysplasia. Seminarsin Perinatology, 37, 85-93.

https://doi.org/10.1053/j.semperi.2013.01.004

[12] Fiaturi, N., Castellot, J.J. and Nielsen, H.C. (2014) Neuregulin-ErbB4 Signaling in the Developing Lung Alveolus: A Brief Review. Journal of Cell Communication and Signalling, 8, 105-111. https://doi.org/10.1007/s12079-014-0233-y

[13] Tang, J.R., Karumanchi, S.A., Seedorf, G., Markham, N. and Abman, S.H. (2012) Excess Soluble Vascular Endothelial Growth Factor Receptor-1 in Amniotic Fluid Impairs Lung Growth in Rats: Linking Preeclampsia with Bronchopulmonary Dysplasia. American Journal of Physiology Lung Cellular and Molecular Physiology, 302, L36-L46.

https://doi.org/10.1152/ajplung.00294.2011

[14] Alshehri, M.A. (2014) Are Preterm Infants at High Altitude at Greater Risk for the Development of Bronchopulmonary Dysplasia? Journalof Tropical Pediatrics, 60, 68-73. https://doi.org/10.1093/tropej/fmt079

[15] Fernández, C.L., Fajardo, C.A., Favareto, M.V., Hoyos, A., Jijón-Letort, F.X., et al. (2014) Oxygen Dependency as Equivalent to Bronchopulmonary Dysplasia at Different Altitudes 
in Newborns $1500 \mathrm{~g}$ at Birth From the SIBEN Network. Journal Perinatology, 34, 538-542. https://doi.org/10.1038/jp.2014.46

[16] Kallapur, S.G., Kramer, B.W. and Jobe, A.H. (2013) Ureaplasma and BPD. Seminars in Perinatology, 37, 94-101. https://doi.org/10.1053/j.semperi.2013.01.005

[17] Been, J.V., Debeer, A., van Iwaarden, J.F., Kloosterboer, N., Passos, V.L., et al. (2010) Early Alterations of Growth Factor Patterns in Bronchoalveolar Lavage Fluid from Preterm Infants Developing Bronchopulmonary Dysplasia. Pediatric Research, 67, 83-89. https://doi.org/10.1203/PDR.0b013e3181c13276

[18] Clyman, R.I. (2013) The Role of Patent Ductus Arteriosus and Its Treatments in the Development of Bronchopulmonary Dysplasia. Seminars in Perinatology, 37, 102-107.

https://doi.org/10.1053/j.semperi.2013.01.006

[19] Gortner, L., Misselwitz, B., Milligan, D., Zeitlin, J., Kollée, L., et al. (2011) Rates of Bronchopulmonary Dysplasia in Very Preterm Neonates in Europe: Results from the MOSAIC Cohort. Neonatology, 99, 112-117. https://doi.org/10.1159/000313024

[20] Collaborative Study Group for Bronchopulmonary Dysplasia of Prematurity in China (2011) Incidence and Risk Factors of Bronchopulmonary Dysplasia in Premature Infants in 10 Hospitals in China. Chinese Journal of Pediatrics, 49, 655-662.

[21] Li, Y., Wei, Q.F., Pan, X.N., Meng, D.H., Wei, W., et al. (2014) Influencing Factors for Severity of Bronchopulmonary Dysplasia in Preterm Infants. Chinese Journal of Contemporary Pediatrics, 16, 1014-1018.

[22] Dunn, M.S., Kaempf, J., de Klerk, A., de Klerk, R., Reilly, M., et al. (2011) Randomized Trial Comparing 3 Approaches to the Initial Rrespiratory Management of Preterm Neonates. Pediatrics, 128, e1069-e1076. https://doi.org/10.1542/peds.2010-3848

[23] Check, J., Gotteiner, N., Liu, X., Su, E., Porta, N., et al. (2013) Fetal Growth Restriction and Pulmonary Hypertension in Premature Infants with Bronchopulmonary Dysplasia. Journal of Perinatology, 33, 553-557. https://doi.org/10.1038/jp.2012.164

[24] Zeitlin, J., El Ayoubi, M., Jarreau, P.H., Draper, E.S., Blondel, B., et al. (2010) Impact of Fetal Growth Restriction on Mortality and Morbidity in a Very Preterm Birth Cohort. Journal of Pediatrics, 157, 733-739. https://doi.org/10.1016/j.jpeds.2010.05.002

[25] Kotecha, S.J., Watkins, W.J., Heron, J., Henderson, J., Dunstan, F.D., et al. (2010) Spirometric Lung Function in School-Age Children: Effect of Intrauterine Growth Retardation and Catch-Up Growth. American Journal of Respiratory and Critical Care Medicine, 181, 969974. https://doi.org/10.1164/rccm.200906-0897OC

[26] Kewitz, G., Wudel, S., Hopp, H., Hopfenmüller, W., Vogel, M., et al. (2008) Below Median Birth Weight in Appropriate-for-Gestational-Age Preterm Infants as a Risk Factor for Bronchopulmonary Dysplasia. Journal of Perinatal Medicine, 36, 359-364. https://doi.org/10.1515/JPM.2008.056

[27] Rozance, P.J., Seedorf, G.J., Brown, A., Roe, G., O’Meara, M.C., et al. (2011) Intrauterine Growth Restriction Decreases Pulmonary Alveolar and Vessel Growth and Causes Pulmonary Artery Endothelial Cell Dysfunction in Vitro in Fetal Sheep. American Journal of Physiology: Lung Cellular and Molecular Physiology, 301, L860-L871. https://doi.org/10.1152/ajplung.00197.2011

[28] Gortner, L., Hilgendorff, A., Bähner, T., Ebsen, M., Reiss, I., et al. (2005) Hypoxia-Induced Intrauterine Growth Retardation: Effects on Pulmonary Development and Surfactant Protein Transcription. Biology of the Neonate, 88, 129-135. https://doi.org/10.1159/000085895

[29] Gortner, L., Reiss, I. and Hilgendorff, A. (2006) Bronchopulmonary Dysplasia and Intrauterine Growth Restriction. The Lancet, 368, 28. 
https://doi.org/10.1016/S0140-6736(06)68964-2

[30] Zana-Taieb, E., Butruille, L., Franco-Montoya, M.L., Lopez, E., Vernier, F., et al. (2013) Effect of Two Models of Intrauterine Growth Restriction on Alveolarization in Rat Lungs: Morphometric and Gene Expression Analysis. PLoS ONE, 8, e78326.

https://doi.org/10.1371/journal.pone.0078326

[31] Doyle, L.W., Ehrenkranz, R.A. and Halliday, H.L. (2013) Dexamethasone Treatment after the First Week of Life for Bronchopulmonary Dysplasia in Preterm Infants: a Systematic Review. Neonatology, 98, 217-224. https://doi.org/10.1159/000286210

[32] Doyle, L.W., Ehrenkranz, R.A. and Halliday, H.L. (2010) Dexamethasone Treatment in the First Week of Life for Bronchopulmonary Dysplasia in Preterm Infants: A Systematic Review. Neonatology, 98, 289-296. https://doi.org/10.1159/000286212

[33] Moisiadis, V.G. and Matthews, S.G. (2014) Glucocorticoids and Fetal Programming Part 1: Outcomes. Nature Reviews Endocrinology, 10, 391-402.

https://doi.org/10.1038/nrendo.2014.73

Submit or recommend next manuscript to SCIRP and we will provide best service for you:

Accepting pre-submission inquiries through Email, Facebook, LinkedIn, Twitter, etc. A wide selection of journals (inclusive of 9 subjects, more than 200 journals)

Providing 24-hour high-quality service

User-friendly online submission system

Fair and swift peer-review system

Efficient typesetting and proofreading procedure

Display of the result of downloads and visits, as well as the number of cited articles Maximum dissemination of your research work

Submit your manuscript at: http://papersubmission.scirp.org/

Or contact ojped@scirp.org 